\title{
Ambulatory Blood Pressure Profiles and Correlation with Cardiovascular Risk Factors in a Sample of 390 University Employees in Tanzania
}

This article was published in the following Dove Press journal: Integrated Blood Pressure Control

\section{Godfrey Chuwa \\ Pilly Chillo}

Department of Internal Medicine, Muhimbili University of Health and Allied Sciences, Dar es Salaam, Tanzania
Correspondence: Pilly Chillo

Department of Internal Medicine, Muhimbili University of Health and Allied Sciences, PO BOX 6500I, Dar es Salaam, Tanzania

$\mathrm{Tel}+255222150603$

Email pchillo2000@yahoo.co.uk
Background: Hypertension is a major risk factor for cardiovascular morbidity and mortality. Increasingly, evidence suggests that 24-hour ambulatory blood pressure (BP) monitoring (ABPM) is more accurate than clinic BP in predicting cardiovascular risk. However, this association has not been widely studied in subSaharan Africa, especially in Tanzania.

Aim: To explore the relationship between 24-hour ABPM profiles and cardiovascular risk factors in comparison with clinic BP among Muhimbili University of Health and Allied Sciences (MUHAS) employees.

Methods: A descriptive cross-sectional study was conducted from October 2018 to February 2019. Socio-demographic and cardiovascular risk information was gathered. We used an automated ABPM device to record 24-hour ambulatory BP. Correlation between BP profiles and cardiovascular risk factors was done using Pearson's correlation coefficient, and independent factors for hypertension were determined using logistic regression analysis. $P$-value of $<0.05$ was considered statistically significant.

Results: In total, 390 employees participated. Their mean age was $40.5 \pm 8.9$ years, and $53.6 \%$ were men. The mean office systolic and diastolic BP were $126 \pm 12 \mathrm{mmHg}$ and $78 \pm 13$ $\mathrm{mmHg}$, respectively, while the corresponding values for mean 24-hour ABPM were $122 \pm 14$ and $75 \pm 10 \mathrm{mmHg}$. The prevalence of hypertension was $23.1 \%$. The prevalence of white coat hypertension was $16.2 \%$, while masked hypertension and nocturnal non-dipping were present in 11.5 and $66.7 \%$, respectively. Overall, the mean 24-hour systolic BP showed the strongest correlations with cardiovascular risk factors while mean office systolic BP showed least. Independent associated factors of hypertension were male gender, age $\geq 40$ years, family history of hypertension, central obesity, raised cholesterol and uric acid levels, all $\mathrm{p}<0.01$.

Conclusion: Compared to office BP, ABPM measurements had stronger correlations with cardiovascular risk factors in this population, and therefore likely to reflect true BP. ABPM has revealed high proportion of masked, white coat and nocturnal non-dipping, supporting use of ABPM to detect these clinically important BP profiles.

Keywords: ambulatory blood pressure, cardiovascular risk factors, hypertension, white coat hypertension, masked hypertension, nocturnal non-dipping, Tanzania, sub-Saharan Africa

\section{Introduction}

Hypertension is a major risk factor for cardiovascular morbidity and mortality worldwide. ${ }^{1}$ In sub Saharan Africa, recent data have shown hypertension to be increasing at an alarming rate, ${ }^{2,3}$ and on average the region already has a higher prevalence of hypertension when compared to that seen in high income countries of Europe and North America. ${ }^{4}$ Hypertension has been considered one of the leading 
health challenges in sub Saharan Africa. ${ }^{5,6}$ Understanding hypertension in the local context is therefore critical for proper prevention and management plans. Most of previous studies in sub Saharan Africa have been based on screening or clinic single-setting blood pressure (BP) measurements to determine the prevalence and associated factors of hypertension. ${ }^{7}$ Although not yet the standard for community hypertension screening, a substantial number of current guidelines have emphasized the use of 24-hour ambulatory BP monitoring (ABPM) to confirm hypertension, especially among new hypertensives. ${ }^{8-10}$ This is because as opposed to clinic BP, ABPM provides a detailed understanding of one's BP changes with daily activities and during sleep, therefore ABPM is able to identify individuals with high BP when measurements are taken at the clinic, known as white coat hypertension as well as identify individuals with normal BP measurements at the clinic but raised while at home; known as masked hypertension. ${ }^{11}$ Furthermore, ABPM can identify individuals with persistent high BP during sleep (nondippers) - itself an independent predictor of stroke. ${ }^{12,13}$

Experience from large longitudinal studies in Europe, Asia and North America has shown that 24-hour ABPM produces better correlations with cardiovascular risk factors and has proven to be more accurate than office BP in predicting cardiovascular morbidity and mortality. ${ }^{14-16}$ In sub Saharan Africa, interest is growing in ABPM, as evidenced by several recent publications from the region, both from hospital settings and in the general population, ${ }^{17-22}$ and even cut-off points for ABPM have been suggested for people in sub Saharan Africa. ${ }^{23}$ A recent meta-analysis found the prevalence of white coat and masked hypertension to be high $(11 \%$ and $14.8 \%$, respectively), especially among urban dwellers across Africa, and recommended the use of out-of-office BP measurements to detect people with these conditions. ${ }^{24}$ However, data on ABPM are still missing in Tanzania, where only one previous study has been carried out among 79 elderly (>70 years) citizens in Northern Tanzania. ${ }^{20}$ There is therefore scarcity of information on ABPM in Tanzania, and information is still limited on how well ABPM relates to the traditional cardiovascular risk factors when compared to clinic BP in our populations. We therefore sought to study the 24-hour ABPM profiles in a sample of Muhimbili University of Health and Allied Sciences (MUHAS) employees and to determine the relationship between ABPM profiles and cardiovascular risk factors in comparison with clinic BP findings.

\section{Materials and Methods \\ Study Design and Duration}

This was a descriptive cross-sectional study conducted over a period of 5 months from October 2018 to February 2019.

\section{Study Area and Population}

The study was conducted at MUHAS - the oldest and largest Public University for Health Sciences in Tanzania, located in the commercial city of Dar es Salaam. During the time of this data collection, MUHAS had two campuses; Muhimbili Campus and Mloganzila Campus (which incorporated the MUHAS Academic Medical Center) with a total of 648 staff (306 academic, and 342 administrative and technical staff), of whom 40.7\% were females. All active MUHAS employees at the time of data collection were invited to participate.

\section{Sample Size}

The sample size was calculated using the Kish-Leslie formula and a total of 351 subjects was enough to determine the prevalence of hypertension at a power of $80 \%$, using the previous known hypertension prevalence of $25.9 \%$ in the Tanzanian adult population. ${ }^{25}$ The sampling frame included all MUHAS employees, and a convenience sample of employees who responded to the request to participate in the study formed the study population.

\section{Data Collection Methods}

A structured questionnaire was used to collect information on socio-demographic characteristics of the participants, previous and family history of cardiovascular disease, as well as information on smoking and alcohol consumption.

\section{Anthropometric Measurements}

Height was measured using a stadiometer and was recorded to the nearest $1 \mathrm{~cm}$. Body weight was measured using a weighing scale (Momert ${ }^{\circledR}$, China), with participants wearing light clothing and without shoes. It was measured in kilograms $(\mathrm{kg})$ and averaged to the nearest tenth of a kilogram. Body mass index (BMI) was calculated by dividing the participants' weight in $\mathrm{kg}$ by the participants' height in meter squared $\left(\mathrm{m}^{2}\right)$. BMI levels were used to categorize participants as normal weight $\left(\leq 24.9 \mathrm{~kg} / \mathrm{m}^{2}\right)$, overweight $\left(25.0-29.9 \mathrm{~kg} / \mathrm{m}^{2}\right)$ and obese $\left(\geq 30 \mathrm{~kg} / \mathrm{m}^{2}\right) .{ }^{26}$ Waist circumference was measured using a tape measure at the level of the umbilicus and was 
recorded to the nearest centimeter. Abdominal obesity was considered present when the waist circumference was $>102 \mathrm{~cm}$ and $88 \mathrm{~cm}$ in men and women respectively. ${ }^{27}$

\section{Blood Pressure Measurements}

Office BP was measured on the participant's left arm using a mercury sphygmomanometer. Measurements were taken in a quiet room after the participant had a 5 minute rest, seated comfortably in a chair with the back and left arm supported, legs uncrossed and the upper arm at the level of the right atrium. A proper cuff size was used, and readings were rounded to the nearest $2 \mathrm{mmHg}$. Three measurements were taken and the average of the last two was recorded as the participant's office BP.

Ambulatory BP measurement was initiated immediately after recording of office BP. Measurements were done using an automated ABPM device (Jawon Medical FA48 ${ }^{\circledR}$, Korea) which has been clinically validated, ${ }^{28}$ and currently in use at the MUHAS Academic Medical Center. $\mathrm{BP}$ recordings were done every 15 minutes between 07:00 and 22:00 hours, and every 30 minutes between 22:00 and 7:00 hours, and followed the criteria for ABPM according to the European Society of Hypertension guidelines. ${ }^{11}$ Participants were given a diary to record the time they went to sleep at night and the time they woke up in the morning, and were asked to avoid vigorous physical activities on the day of the test. A minimum number of 20 daytime, and 7 nighttime ABPM recordings was set as sufficient recordings for inclusion in the analysis. ${ }^{11}$

\section{Definitions for Blood Pressure Findings}

Office hypertension was defined as BP of more than or equal to $140 \mathrm{mmHg}$ systolic and/or $90 \mathrm{mmHg}$ diastolic. ${ }^{29}$ Ambulatory hypertension was defined as average daytime ABPM of $\geq 135 \mathrm{mmHg}$ systolic and/or $85 \mathrm{mmHg}$ diastolic. White coat hypertension was defined as office BP of $\geq 140$ / $90 \mathrm{mmHg}$ with average daytime ABPM of $<135 / 85$ $\mathrm{mmHg}$. Masked hypertension was defined as clinic BP of $<140 / 90 \mathrm{mmHg}$ with average daytime ABPM $\geq 135 / 85$ $\mathrm{mmHg}$, while we defined nocturnal non-dipping as a less than $10 \%$ decrease in systolic and/or diastolic BP from day to night. ${ }^{11}$ We further defined 24-hour hypertension as average 24-hour ABPM of $\geq 130 \mathrm{mmHg}$ systolic and/or $\geq 80 \mathrm{mmHg}$ diastolic, nocturnal hypertension as average nighttime ABPM of $\geq 120 \mathrm{mmHg}$ systolic and/or $\geq 70$ $\mathrm{mmHg}$ diastolic, and isolated nocturnal hypertension as presence of nocturnal hypertension with normal average daytime ABPM. ${ }^{11,30}$ Extreme nocturnal dipping was defined as average day-to-night BP reduction of $>20 \%$, while reserve dipping was defined as average day-tonight BP reductions of $<0 \%{ }^{11,30}$ Participants were categorized as true normotensives when they had normal BP readings by both office and $\mathrm{ABPM}$, and as sustained hypertensives when they had elevated BP readings by both clinic and ABPM. ${ }^{11}$

\section{Laboratory Investigations}

All participants underwent blood tests. The tests included serum glucose levels, serum lipid profile (total cholesterol, low-density lipoprotein cholesterol, high-density lipoprotein cholesterol and triglycerides levels), serum creatinine and serum uric acid levels. Participants were asked to fast overnight before blood collection the next morning. Four milliliters of blood were collected and all blood tests, except fasting blood glucose, were analyzed at MUHAS Academic Medical Centre laboratory using the Architect Plus ci410 ${ }^{\circledR}$ analyzer. Fasting blood glucose was analyzed on-spot using a portable glucometer (Accucheck Performa $^{\circledR}$, Roche). Diabetes was defined as fasting blood glucose of $7.0 \mathrm{mmol} / 1$ or previous diagnosis of diabetes mellitus with use of medications. ${ }^{31}$ Hypercholesterolemia was defined as total cholesterol level $\geq 5.2 \mathrm{mmol} / 1$, while elevated low density lipoprotein cholesterol was defined as serum low density lipoprotein cholesterol $\geq 3.4 \mathrm{mmol} / \mathrm{l}^{32}$ High density lipoprotein cholesterol was considered low when it was $<1 \mathrm{mmol} / 1$. Serum creatinine was used to calculate estimated glomerular filtration rate (eGFR), using the Modification of Diet in the Renal Disease (MDRD) equation, ${ }^{33}$ and the eGFR was considered low when it is $<60 \mathrm{~mL} / \mathrm{min} / 1.73 \mathrm{~m}^{2}$. Serum uric acid level was considered elevated when it is $>7.0 \mathrm{mg} / \mathrm{dl}^{34}$

\section{Data Handling and Analysis}

Data obtained from the questionnaires were entered electronically in the computerized software program, statistical package of social sciences (SPSS) version 20 for Windows for data analysis. There was cross checking of filled questionnaires after data collection for quality control of data. The main outcome variable was ambulatory BP findings. Continuous variables were expressed as mean $\pm \mathrm{SD}$ or as median and interquartile ranges. Comparisons of categorical variables between groups were performed using chisquared test or Fisher's exact test, while comparisons between means were determined using Student's $t$-test. Bivariate linear correlations were assessed using 
Pearson's correlation coefficient to determine the association between ABPM profiles, office measurements, and continuous demographic and cardiovascular risk factor variables. Multivariate logistic regression analysis was used to determine independent associations between the presence of hypertension and binary variables. All tests were two sided and a $p$-value of less than 0.05 was considered statistically significant.

\section{Ethical Considerations}

The study was conducted in accordance with the Helsinki Declaration on studies involving human subjects. Ethical clearance was obtained from the Directorate of Research and Publication at Muhimbili University of Health and Allied Sciences (MUHAS) and permission to conduct the study was obtained from MUHAS administration. All participants signed an informed consent form after they fully understood the information and agreed to participate in the study. Confidentiality and privacy were assured.

\section{Results}

\section{Socio-Demographic and Clinical Characteristics}

In total, 390 MUHAS employees were studied, 78.2\% were from Muhimbili campus and $53.6 \%$ were men. The mean \pm SD age of the total study population was $40.5 \pm 8.9$ years (range 24-59 years). Positive family history of hypertension was found in $35.4 \%$ of the participants while $15.6 \%$ and $2.1 \%$ were known hypertensives and diabetics, respectively. Alcohol intake (self-reported regular intake) was present in $44.1 \%$ of the total population, with men being a larger proportion of alcohol drinkers (66\%) when compared to women $(18.8 \%)$, p $<0.0001$. Only $13(3.3 \%)$ participants (all men) reported to have ever smoked cigarettes. Table 1 summarizes demographic and clinical characteristics in the total population.

Laboratory findings are presented in Table 2. In the total population, the mean fasting blood glucose, total cholesterol, triglycerides and uric acid levels were all in the normal range. However, there were 13 (3.3\%) participants with raised fasting blood glucose, 92 (23.6\%) participants with hypercholesterolemia, and 53 (13.6\%) with hyperuricemia, Table 2 . Likewise, the mean serum creatinine of the total population was normal $(86.3 \mu \mathrm{mol} / \mathrm{l})$, but $17(4.4 \%)$ of participants had lower estimated glomerular filtration rate (all women) indicating impaired renal function, Table 2.

\section{BP Profiles and Correlation with Cardiovascular Risk Factors}

Table 3 shows office and ambulatory BP findings in men and women separately, and in the total population. All (100\%) participants had successful ABPM recordings as per defined criteria for inclusion, and were analyzed. Men had significantly higher mean values for all systolic and diastolic BP measurements. In the total population, 82 (21\%) participants were found to have office hypertension (i.e., office BP $\geq 140$ systolic and/or $\geq 90 \mathrm{mmHg}$ diastolic). Sixty-four (16.4\%) participants were found to have hypertension by ambulatory daytime BP (i.e., mean ambulatory day-time BP $\geq 135 \mathrm{mmHg}$ systolic and/or $\geq 85 \mathrm{mmHg}$ diastolic). Ambulatory day-time hypertension was significantly more prevalent in men $(22 \%)$ than in women $(9.9 \%), p=0.001$, Table 3. Other ABPM findings were as seen in Table 3.

In the total population (excluding those on treatment for hypertension, $\mathrm{n}=55$ ), an analysis of the different hypertension phenotypes showed 242 (72.2\%) participants were true normotensive, 13 (3.9\%) had sustained hypertension, $58(17.3 \%)$ had white coat hypertension and the remaining $22(6.6 \%)$ had masked hypertension.

Univariate correlations of mean systolic and diastolic BP with continuous variables are shown in Table 4 and in Figure $1 \mathrm{~A}$ and $\mathrm{B}$. There were significant correlations between most of the tested known risk factors for hypertension and mean ambulatory daytime systolic and diastolic BP measurements.

Figure $1 \mathrm{~A}$ and $\mathrm{B}$ compare the strengths of correlations between continuous variables age, body mass index, waist circumference, fasting blood sugar, total cholesterol, triglycerides, uric acid, serum creatinine and estimated GFR, with mean systolic (Figure 1A) and diastolic (Figure 1B) BP for office and ambulatory BP profiles. By comparison, the mean 24-hour ambulatory systolic BP performed best when compared to other ambulatory and office systolic BP findings in terms of best overall correlations with the variables tested, while office systolic BP performed least. Considering diastolic BP, the mean ambulatory sleep time diastolic BP had the overall strongest correlation with the tested variables, and again office diastolic BP performed least.

\section{Prevalence and Associated Factors of Hypertension}

In this study, overall hypertension was defined as raised ambulatory daytime BP of $\geq 135 \mathrm{mmHg}$ systolic and/or $\geq 85 \mathrm{mmHg}$ diastolic or known hypertensive on 
Table I Demographic and Clinical Characteristic of Study Participants

\begin{tabular}{|c|c|}
\hline Characteristics & n (\%) or Mean \pm SD \\
\hline Age (years) & $40.5 \pm 8.9$ \\
\hline \multicolumn{2}{|l|}{ Age groups (years); n (\%) } \\
\hline$<30$ & $67(17.2)$ \\
\hline $31-40$ & $138(35.4)$ \\
\hline $4 I-50$ & $126(32.3)$ \\
\hline$>50$ & $59(15.1)$ \\
\hline \multicolumn{2}{|l|}{ Work station; n (\%) } \\
\hline Mloganzila campus & $85(21.8)$ \\
\hline Muhimbili campus & $305(78.2)$ \\
\hline \multicolumn{2}{|l|}{ Education level; n (\%) } \\
\hline Primary & $15(3.8)$ \\
\hline Secondary & $59(15.1)$ \\
\hline College/University & $316(8 I)$ \\
\hline \multicolumn{2}{|l|}{ Staff category; n (\%) } \\
\hline Academic staff and Doctors & $66(16.9)$ \\
\hline Nurses & $54(13.8)$ \\
\hline Administrative and Technical staff & $270(69.2)$ \\
\hline \multicolumn{2}{|l|}{ Marital status; n (\%) } \\
\hline Single & $94(24.1)$ \\
\hline Married & $280(71.8)$ \\
\hline Divorced/Widowed & $16(4.1)$ \\
\hline Weight (kg) & $68.9 \pm 11.3$ \\
\hline Height (m) & $1.60 \pm 0.06$ \\
\hline Body Mass Index $\left(\mathrm{kg} / \mathrm{m}^{2}\right)$ & $27.1 \pm 4.6$ \\
\hline \multicolumn{2}{|l|}{ Obesity status; n (\%) } \\
\hline Normal & $125(32.0)$ \\
\hline Overweight & $140(35.9)$ \\
\hline Obese & $125(32.1)$ \\
\hline Positive family history of hypertension; $\mathrm{n}$ (\%) & $138(35.4)$ \\
\hline Known hypertensive; n (\%) & $61(15.6)$ \\
\hline Known diabetic; n (\%) & $8(2.1)$ \\
\hline Consuming alcohol; n (\%) & $172(44.1)$ \\
\hline Ever smoked; n (\%) & $13(3.3)$ \\
\hline
\end{tabular}

medications. In the total population, 90 (23.1\%) participants fulfilled the definition of having hypertension while the remaining $300(76.9 \%)$ did not have hypertension. Of the 90 participants with hypertension $61(67.8 \%)$ were known to have hypertension while 29 (32.2\%) were newly diagnosed during this screening. Furthermore, out of the 61 previously known hypertensives, 35 (57.4\%) were found to have raised BP on mean daytime ABPM,
Table 2 Laboratory Findings of Study Participants

\begin{tabular}{|l|c|}
\hline Laboratory Findings & $\begin{array}{c}\text { n (\%) or Mean } \\
\text { ISD }\end{array}$ \\
\hline Fasting blood glucose (mmol/l) & $4.5 \pm 0.6$ \\
Proportions with diabetes mellitus n (\%) & $13(3.3)$ \\
Total serum cholesterol (mmol/l) & $4.5 \pm 0.9$ \\
Proportions with raised total cholesterol n (\%) & $92(23.6)$ \\
Serum HDL-Cholesterol (mmol/l) & $1.19 \pm 0.13$ \\
Serum LDL-Cholesterol (mmol/l) & $2.4 \pm 0.4$ \\
Proportion with raised LDL-Cholesterol, $\mathrm{n}(\%)$ & $18(4.6)$ \\
Serum Triglycerides (mmol/l) & $1.53 \pm 0.27$ \\
Proportion with raised Triglycerides, $\mathrm{n}(\%)$ & $87(22.3)$ \\
Serum Uric acid (mmol/l) & $0.36 \pm 0.12$ \\
Proportions with hyperuricemia, $\mathrm{n}(\%)$ & $53(13.6)$ \\
Serum Blood Urea Nitrogen (mmol/l) & $3.96 \pm 0.93$ \\
Serum Creatinine $(\mu \mathrm{mol} / \mathrm{l})$ & $86.3 \pm 17.4$ \\
Estimated GFR (mL/min /l.73 m2) & $94.9 \pm 23.3$ \\
Proportions with eGFR <60, $\mathrm{n}(\%)$ & $17(4.4 \%)$ \\
\hline
\end{tabular}

Abbreviations: HDL, high density lipoprotein; LDL, low density lipoprotein; eGFR, estimated glomerular filtration rate.

indicating uncontrolled hypertension in this group. Compared to participants without hypertension, those with hypertension were more likely to be men, were older and were more likely to be from Muhimbili campus, all $\mathrm{p}<0.05$, Table 5. Furthermore, hypertensive participants were more likely to have smoked cigarettes as well as more likely to have positive family history of hypertension, Table 5.

Socio-demographic, clinical and laboratory parameters that showed significant associations with being hypertensive among MUHAS employees were entered in a multivariable logistic regression analysis model. After removal of correlated parameters (e.g., weight and BMI), the final best fitting model included gender, age, family history of hypertension, central adiposity, hypercholesterolemia and hyperuricemia. In this multivariate logistic regression analysis, the independent associated factors for the diagnosis of hypertension were male gender, age $\geq 40$ years, positive family history of hypertension, central obesity, as well as high serum total cholesterol and elevated uric acid levels, $\mathrm{p}<0.05$ for all, Table 6 .

\section{Discussion}

Blood pressure of an individual increases with age and is closely related to other cardiovascular risk factors namely overweight and obesity, dyslipidemia, insulin resistance and other components of metabolic syndrome. ${ }^{35}$ Therefore how close the person's blood pressure is to 
Table 3 Office and 24-Hour Ambulatory Blood Pressure Findings of Study Participants

\begin{tabular}{|c|c|c|c|c|}
\hline BP Findings & Men $(n=209)$ & Women $(n=181)$ & Total $(\mathbf{N}=390)$ & ${ }^{*} p$-value \\
\hline Office Systolic BP (mmHg) & $128 \pm 12$ & $124 \pm 13$ & $126 \pm 12$ & 0.001 \\
\hline Office Diastolic BP (mmHg) & $80 \pm 14$ & $76 \pm 11$ & $78 \pm 13$ & 0.004 \\
\hline Daytime Systolic BP (mmHg) & $129 \pm 12$ & $123 \pm 11$ & $126 \pm 12$ & $<0.001$ \\
\hline Daytime Diastolic BP (mmHg) & $79 \pm 10$ & $75 \pm 10$ & $77 \pm 10$ & $<0.001$ \\
\hline Sleep time Systolic BP $(\mathrm{mmHg})$ & $121 \pm 17$ & $116 \pm 17$ & $118 \pm 18$ & 0.006 \\
\hline Sleep time Diastolic BP $(\mathrm{mmHg})$ & $74 \pm 11$ & $70 \pm 13$ & $72 \pm 12$ & 0.002 \\
\hline 24-hour Systolic BP (mmHg) & $125 \pm 13$ & $119 \pm 14$ & $122 \pm 14$ & $<0.001$ \\
\hline 24-hour Diastolic BP (mmHg) & $77 \pm 10$ & $72 \pm 11$ & $75 \pm 10$ & $<0.001$ \\
\hline Participants with Office hypertension, n (\%) & $49(23.4)$ & $33(18.2)$ & $82(21.0)$ & 0.208 \\
\hline Participants with Ambulatory Daytime hypertension, n (\%) & $46(22.0)$ & $18(9.9)$ & $64(16.4)$ & 0.001 \\
\hline Participants with 24-hr hypertension, n (\%) & $101(48.3)$ & $53(29.3)$ & $154(39.5)$ & $<0.001$ \\
\hline Participants with nocturnal hypertension, $\mathrm{n}(\%)$ & $136(65.1)$ & $78(43.1)$ & $214(54.9)$ & $<0.001$ \\
\hline Participants with isolated nocturnal hypertension, n (\%) & $91(43.5)$ & $66(36.5)$ & $157(40.3)$ & 0.155 \\
\hline Participants with white coat hypertension, n (\%) & $30(14.4)$ & $33(18.2)$ & $63(16.2)$ & 0.299 \\
\hline Participants with masked hypertension, n (\%) & $27(12.9)$ & $18(9.9)$ & $45(11.5)$ & 0.359 \\
\hline Participants with nocturnal non-dipping, n (\%) & $133(63.6)$ & $127(70.2)$ & $260(66.7)$ & 0.173 \\
\hline Participants with extreme dipping, n (\%) & $23(11.0)$ & $20(11.0)$ & $43(11.0)$ & 0.989 \\
\hline Participants with reverse dipping, n (\%) & $55(26.3)$ & $39(21.5)$ & $94(24.1)$ & 0.272 \\
\hline Participants with normal dipping, n (\%) & $52(24.9)$ & $28(15.5)$ & $80(20.5)$ & 0.022 \\
\hline
\end{tabular}

Notes: Results are mean \pm SD unless stated otherwise; *p-value, comparing differences between men and women.

these factors, is related to the true blood pressure of that individual. We found in this study that BP profiles obtained from ABPM measurements were more strongly related to other cardiovascular risk factors when compared to office BP measurements. Our findings are in keeping with previous studies that have shown ABPM to be superior to office BP in determining an individual's cardiovascular risk as well as the cardiovascular risk outcome. ${ }^{36,37}$ It is however important to note that the superiority of ABPM over conventional office BP in the follow-up of hypertensive patients is still controversial, and is an area of active research. ${ }^{38}$ Furthermore, the cost of ABPM may be a limiting factor in Tanzania and many other sub Saharan African countries, as most of patients still depend on outof-pocket financing to cover their medical bills. ${ }^{39,40}$ In this study the mean 24-hour systolic BP out-performed other ABPM profiles as well as office BP in terms of the strength of correlation with CV risk factors. This finding is similar to that found by investigators in Brazil as well as in a large population-based study that included subjects from Europe, Asia and South America. ${ }^{41,42}$ In the study by Yang et al, ${ }^{42}$ mean 24-hour systolic BP had the strongest hazard ratio of predicting cardiovascular events when compared to other ABPM profiles.

The fact that mean ambulatory BP showed stronger correlations with the modifiable risk factors like hypercholesterolemia, hyperuricemia and obesity, suggests that most of the BP increase in this population is related to lifestyle, and that control measures should target lifestyle modification. Furthermore, estimated GFR as a measure of renal function is strongly related to one's $\mathrm{BP}$ and may indicate the effect of sustained high BP on the kidneys. Our results show that sleep time BP was more strongly related to one's levels of estimated GFR in this population, and the higher the mean night-time BP, the lower the estimated GFR. Previous studies have found nocturnal high BP to predict development of chronic kidney disease (CKD) in the general population. ${ }^{43}$ On the other hand, patients with CKD have been found to have less BP fall during sleep, ${ }^{44}$ indicating that the relationship between nighttime BP and renal function is two-way. As the present study was cross-sectional, the observed association can be a result or an underlying factor for future kidney dysfunction, therefore follow-up studies are needed to further understand the association between ABPM profiles and development of CKD in our African populations.

We found $16 \%$ of our study participants had white coat hypertension, which is within the range of white coat hypertension reported in documented literature of 9-23\%. ${ }^{45}$ This proportion is also similar to that found by investigators in South Africa where white coat hypertension was present in $18 \%$ of all participants in that study. ${ }^{46}$ 
Table 4 Correlates of Ambulatory Day-Time Mean Systolic and Diastolic Blood Pressure

\begin{tabular}{|c|c|c|c|c|}
\hline \multirow[t]{2}{*}{ Factors } & \multicolumn{2}{|c|}{ Mean Daytime SBP } & \multicolumn{2}{|c|}{ Mean Daytime DBP } \\
\hline & $\mathbf{r}$ & p-value & $\mathbf{r}$ & p-value \\
\hline Age (years) & 0.323 & $<0.001$ & 0.247 & $<0.001$ \\
\hline Weight (kg) & 0.256 & $<0.001$ & 0.206 & $<0.001$ \\
\hline Height (m) & -0.094 & 0.065 & -0.078 & 0.126 \\
\hline BMI $\left(\mathrm{kg} / \mathrm{m}^{2}\right)$ & 0.286 & $<0.001$ & 0.219 & $<0.001$ \\
\hline Waist circumference & 0.139 & 0.006 & 0.088 & 0.081 \\
\hline Fasting Blood Sugar $(\mathrm{mmol} / \mathrm{l})$ & 0.446 & $<0.001$ & 0.316 & $<0.001$ \\
\hline Total Cholesterol (mmol/l) & 0.707 & $<0.001$ & 0.49 & $<0.001$ \\
\hline HDL-Cholesterol (mmol/l) & 0.733 & $<0.001$ & 0.306 & $<0.001$ \\
\hline LDL-Cholesterol (mmol/l) & 0.439 & $<0.001$ & 0.351 & $<0.001$ \\
\hline Triglyceride $(\mathrm{mmol} / \mathrm{l})$ & 0.49 & $<0.001$ & 0.285 & $<0.001$ \\
\hline Uric acid (mmol/l) & 0.652 & $<0.001$ & 0.496 & $<0.001$ \\
\hline Serum Creatinine $(\mu \mathrm{mol} / \mathrm{l})$ & 0.67 & $<0.001$ & 0.439 & $<0.001$ \\
\hline eGFR (mL /min / $1.73 \mathrm{~m} 2)$ & -0.362 & $<0.001$ & -0.208 & $<0.001$ \\
\hline Urea Nitrogen $(\mu \mathrm{mol} / \mathrm{l})$ & 0.465 & $<0.001$ & 0.284 & $<0.001$ \\
\hline
\end{tabular}

Abbreviations: HDL, high density lipoprotein; LDL, low density lipoprotein; eGFR, estimated glomerular filtration rate.

However, our findings contrast those obtained in a sample of rural individuals from Kenya ${ }^{19}$ as well as from a cohort of elderly participants in Tanzania, ${ }^{20}$ most likely due to differences in the studied populations. The implication for this finding is that up to $16 \%$ of individuals in our study population could have been subjected to unnecessary use of antihypertensive medications if only office BP was used to diagnose hypertension.

We found in this study that the proportion of participants with masked hypertension was $11.5 \%$, meaning these participants would have been considered normotensive if only office BP measurements were used to screen for hypertension. This figure lies within the world average prevalence of $6.7-20 \%,{ }^{45}$ as well as within the prevalence reported from studies in sub Saharan Africa (5.1-16.1\%). ${ }^{19,20,22}$ The slight differences from ours and the studies from the region are likely due to the differences in the studied population in terms of age and urban-rural settings between the studies. Masked hypertension has been considered harmful and it requires treatment, as several large population studies have shown that the condition carries an increased risk of all-cause as well as cardiovascular mortality. ${ }^{47,48}$ In the Japanese general population cohort for example, masked hypertension was associated with a 2-fold increased risk of first stroke. ${ }^{47}$ Given the high and increasing rate of cardiovascular diseases and stroke in our African populations, ${ }^{49}$ there is a need to actively look for masked hypertension, especially in individuals with overall increased cardiovascular risk profile, in order to detect this otherwise nonbenign condition.

Lack of normal BP circadian rhythm of 10-15\% decreased BP during sleep is known as nocturnal nondipping and is associated with increased development of target organ damage such as left ventricular hypertrophy and sub-clinical systolic dysfunction, ${ }^{50}$ as well as occurrence of cardiovascular and more importantly cerebrovascular events. ${ }^{12,42}$ We found that a high proportion $(66.7 \%)$ of participants in our sample had nocturnal non-dipping. These findings are similar to the finding in a sample of an elderly cohort in Tanzania where non-dipping was present in $69.6 \% .^{20}$ The anxiety of having a BP device during sleep could explain some of the reasons for high prevalence of non-dipping in our sample, as suggested by other investigators. $^{20,51}$ However, linked to stroke, this trend warrants further investigations as in Tanzania stroke is very prevalent, ${ }^{52}$ and it is possible that the phenomenon partly explains the high stroke rate in the country.

Our study has revealed that among known hypertensives on medications, more than half $(57.4 \%)$ had their BP uncontrolled in this otherwise educated middle class population. This is similar to a finding from a systematic review of literature in sub Saharan African countries ${ }^{53}$ and calls for more aggressive BP control measures. In an interesting observation recently published by Nsutebu et al, use of ABPM improved clinical decision-making for 


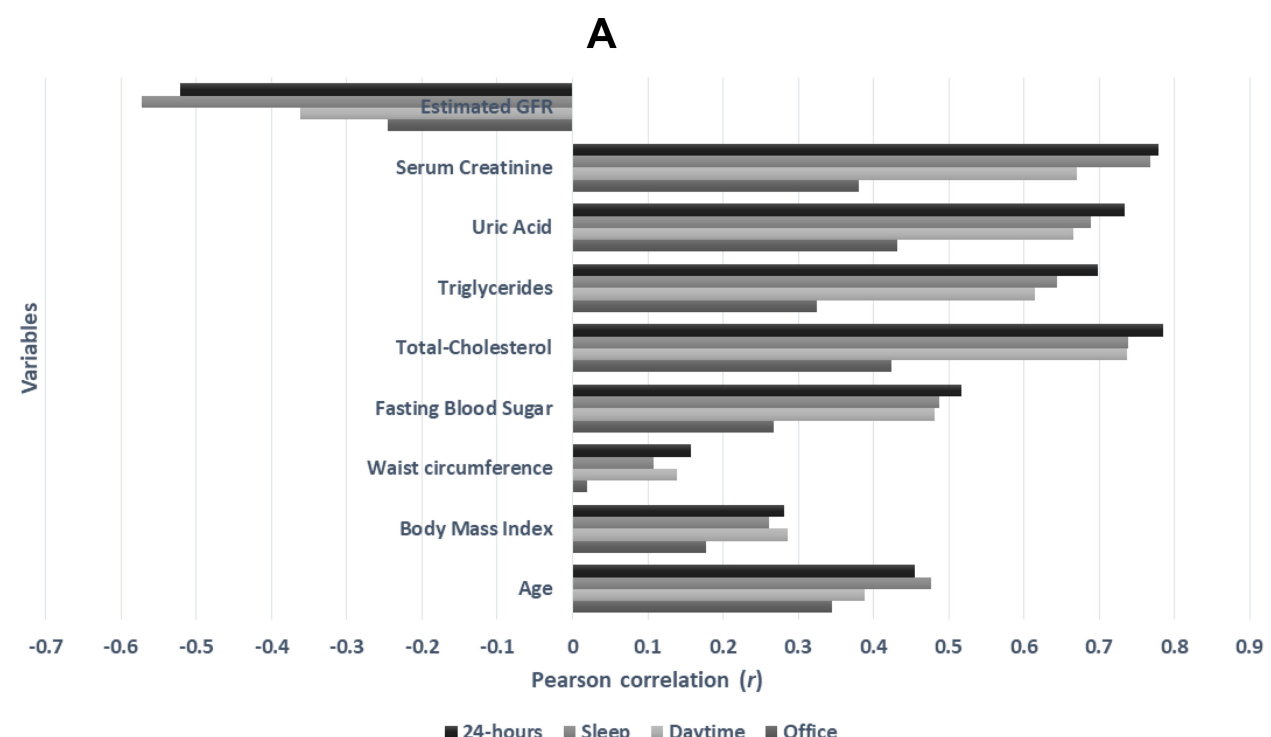

24-hours = Sleep Daytime = Office

B

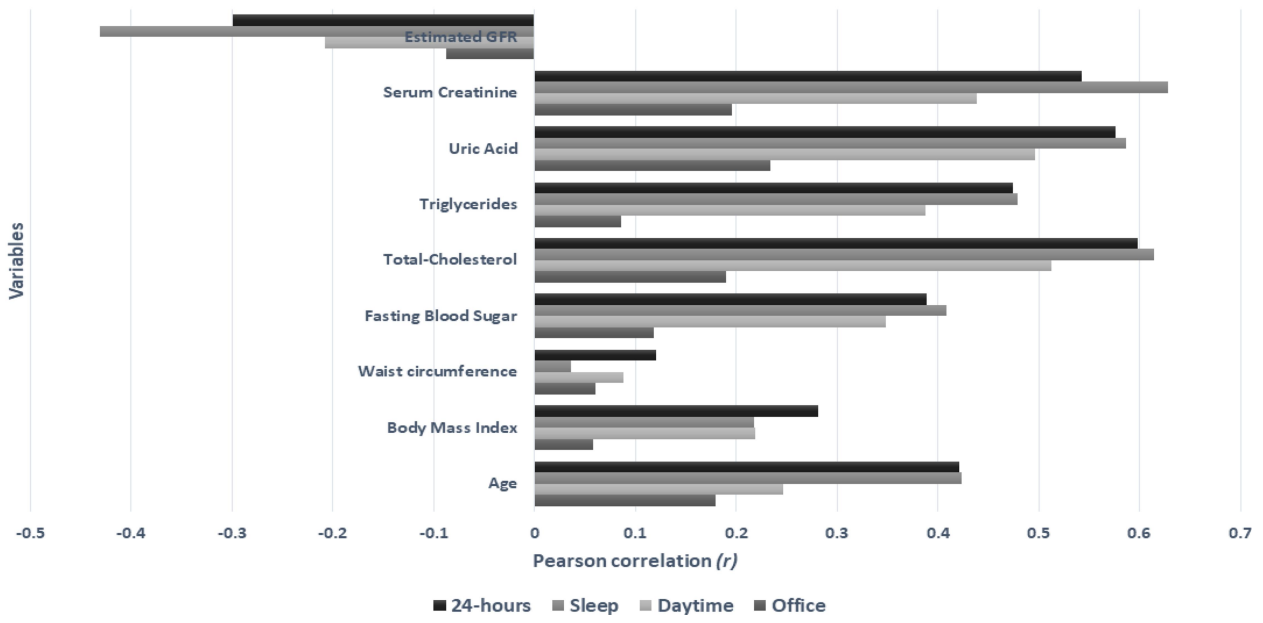

Figure I (A) Univariate correlates of office, day-time, sleep and 24-hour mean systolic BP. (B) Univariate correlates of office, day-time, sleep and 24-hour mean diastolic BP.

antihypertensive therapy review and therefore improved BP control in a cohort of hypertensive adults attending a cardiac clinic in Kumasi, Ghana, ${ }^{22}$ adding to the importance of ABPM in our settings.

The overall prevalence of hypertension found in this study (23.1\%) is almost similar to the Tanzania's hypertension prevalence of $25.9 \%$ obtained in the WHO STEPS survey. ${ }^{25}$ This finding is also similar to a similar population of nurses and teachers from a study by Guwatudde et al including data from four SSA countries, including Tanzania. ${ }^{54}$ Furthermore, the independent associations of hypertension found in this study reflect the known traditional risk factors for hypertension previously documented in the region ${ }^{55}$ and elsewhere. ${ }^{56}$ Male gender was strongly associated with the diagnosis of hypertension at an 8-fold increased likelihood in our cohort. This gender disparity has been reported by others and especially among younger adults. ${ }^{57}$ Of note, our population was also young, with mean age of 40 years, likely explaining the great disparity in hypertension prevalence. On the other hand, increasing age, higher waist circumference, hyperlipidemia and hyperuricemia were all independently associated with the diagnosis of hypertension in this cohort. These factors reflect the general knowledge that although termed "essential", hypertension is always associated with inherent genetic risk (positive family history) ${ }^{58}$ normal aging physiology (increasing age) ${ }^{59}$ and superimposed with lifestyle risks (obesity, hyperlipidemia, hyperuricemia). ${ }^{60}$

Our relatively larger study population compared to the previous study from Tanzania is one of the strengths of this study. The limitations of this study include its cross-sectional nature and therefore we could not establish a causal relationship between the presence of hypertension and the risk factors 
Table 5 Socio-Demographic, Clinical and Laboratory Findings in Study Participants with and without Hypertension

\begin{tabular}{|c|c|c|c|}
\hline Characteristics & Non-Hypertensive $(n=300)$ & Hypertensive $(\mathrm{n}=90)$ & p-value \\
\hline Women, n (\%) & $150(50)$ & 31 (34.4) & 0.009 \\
\hline Age (years) & $38.5 \pm 8.6$ & $47.2 \pm 6.1$ & $<0.001$ \\
\hline \multicolumn{4}{|l|}{ Staff category, n (\%) } \\
\hline Nurses & $47(15.7)$ & $7(7.8)$ & 0.02 \\
\hline Academic staff and Doctors & $56(18.7)$ & $10(I I . I)$ & \\
\hline Administrative and Technical staff & $197(65.7)$ & $73(81.1)$ & \\
\hline \multicolumn{4}{|l|}{ Marital status, n (\%) } \\
\hline Single & $82(27.3)$ & $12(13.3)$ & $<0.001$ \\
\hline Married & $2 \mid 4(7 \mid .3)$ & $66(73.3)$ & \\
\hline Divorced/widowed & $4(1.3)$ & $12(13.3)$ & \\
\hline Family history of hypertension, $\mathrm{n}(\%)$ & $79(26.3)$ & $59(65.6)$ & $<0.001$ \\
\hline Ever smoked, n (\%) & $5(1.7)$ & $8(8.9)$ & 0.001 \\
\hline Consuming alcohol, n (\%) & $127(42.3)$ & $45(50.0)$ & 0.199 \\
\hline Body Mass Index $\left(\mathrm{kg} / \mathrm{m}^{2}\right)$ & $26 \pm 4.2$ & $31 \pm 3.8$ & $<0.001$ \\
\hline \multicolumn{4}{|l|}{ Obesity class, n (\%) } \\
\hline Normal weight & $125(4 \mid .7)$ & $0(0.0)$ & $<0.001$ \\
\hline Overweight & $114(38.0)$ & $26(28.9)$ & \\
\hline Obese & $61(20.3)$ & $64(7 I . I)$ & \\
\hline Waist circumference $(\mathrm{cm})$ & $88 \pm 8$ & $92 \pm 7$ & $<0.001$ \\
\hline Raised waist circumference, $\mathrm{n}(\%)$ & $51(17.0)$ & $27(30.0)$ & 0.007 \\
\hline Fasting Blood Glucose (mmol/l) & $4.4 \pm 0.3$ & $4.9 \pm 1.0$ & $<0.001$ \\
\hline Raised glucose, n (\%) & $0(0.0)$ & $13(14.4)$ & $<0.001$ \\
\hline Total Cholesterol $(\mathrm{mmol} / \mathrm{l})$ & $4.3 \pm 0.5$ & $5.4 \pm 1.1$ & $<0.001$ \\
\hline Raised Total Cholesterol, n (\%) & $31(10.3)$ & $61(67.8)$ & $<0.001$ \\
\hline Triglycerides (mmol/l) & $1.46(0.17)$ & I.76 (0.37) & $<0.001$ \\
\hline Raised Triglycerides level, n (\%) & $43(14.3)$ & $44(48.9)$ & $<0.001$ \\
\hline Uric Acid level (mmol/l) & $0.32 \pm 0.08$ & $0.48 \pm 0.16$ & $<0.001$ \\
\hline Raised Uric Acid, n (\%) & $12(4.0)$ & $41(45.6)$ & $<0.001$ \\
\hline Serum Creatinine $(\mu \mathrm{mol} / \mathrm{l})$ & $82 \pm 12$ & $102 \pm 23$ & $<0.001$ \\
\hline eGFR $(\mathrm{mL} / \mathrm{min} / 1.73 \mathrm{~m} 2)$ & $99 \pm 21$ & $80 \pm 26$ & $<0.001$ \\
\hline Proportion with eGFR <60, n (\%) & $6(2.0)$ & II (12.2) & $<0.001$ \\
\hline
\end{tabular}

Note: Results are mean $\pm S D$, unless stated otherwise.

Abbreviation: eGFR, estimated glomerular filtration rate.

detected. Furthermore, because participants were enrolled as a convenience sample of those that responded to the request to participate, the findings may not be generalizable to all MUHAS employees. The studied population is unique since it was mainly people from middle class educated population, and therefore comparisons can only be done with similar study populations. Also, the collected data were not comprehensive to calculate individual participants' cardiovascular risk scores. However, the main objective was to determine how well (compared to office BP) ABPM measurements are related to the person's cardiovascular risk profile as well as to determine the rate of occurrences of white coat, masked and nocturnal 
Table 6 Independent Associations of Hypertension Among MUHAS Employees Obtained in Multivariate Logistic Regression Analysis

\begin{tabular}{|c|c|c|c|}
\hline Variables & Odds Ratio & $95 \% \mathrm{Cl}$ & p-value \\
\hline Male gender & 7.96 & $2.50-25.30$ & $<0.001$ \\
\hline Positive family history of hypertension & 5.60 & $2.61-12.04$ & $<0.001$ \\
\hline Central obesity & 8.98 & $2.72-29.70$ & $<0.001$ \\
\hline Elevated total cholesterol & 3.84 & $1.56-9.50$ & 0.004 \\
\hline Elevated uric acid & 7.90 & $2.55-24.43$ & $<0.001$ \\
\hline
\end{tabular}

non-dipping profiles in our setting, and we feel this has been reasonably achieved.

\section{Conclusion}

Compared to office BP, ABPM measurements had stronger correlations with cardiovascular risk factors in this population of University employees, and therefore likely to reflect their true BP. Furthermore, use of ABPM has revealed a high proportion of masked hypertension, white coat hypertension and nocturnal non-dipping, supporting use of ABPM to detect these clinically important BP findings.

\section{Disclosure}

The authors report no conflicts of interest for this work.

\section{References}

1. Forouzanfar MH, Alexander L, et al. Global, regional, and national comparative risk assessment of 79 behavioural, environmental and occupational, and metabolic risks or clusters of risks in 188 countries, 1990-2013: a systematic analysis for the Global Burden of Disease Study 2013. Lancet. 2015;386(10010):2287-2323.

2. Mills KT, Stefanescu A, He J. The global epidemiology of hypertension. Nat Rev Nephrol. 2020;16(4):223-237. doi:10.1038/ s41581-019-0244-2

3. Beaney T, Schutte AE, Stergiou GS, et al. May measurement month 2019: the global blood pressure screening campaign of the International Society of Hypertension. Hypertension. 2020;76 (2):333-341. doi:10.1161/HYPERTENSIONAHA.120.14874

4. Yuyun MF, Sliwa K, Kengne AP, Mocumbi AO, Bukhman G. Cardiovascular diseases in Sub-Saharan Africa compared to high-income countries: an epidemiological perspective. Glob Heart. 2020;15(1):15. doi:10.5334/gh.403

5. Dzudie A, Rayner B, Ojji D, et al. Roadmap to achieve 25\% hypertension control in Africa by 2025. Glob Heart. 2018;13(1):45-59. doi:10.1016/j.gheart.2017.06.001

6. Campbell NR, Bovet P, Schutte AE, Lemogoum D, Nkwescheu AS. High blood pressure in Sub-Saharan Africa: why prevention, detection, and control are urgent and important. J Clin Hypertens. 2015;17 (9):663-667. doi:10.1111/jch.12599

7. Gomez-Olive FX, Ali SA, Made F, et al. Regional and sex differences in the prevalence and awareness of hypertension: an H3Africa AWI-Gen Study across 6 sites in Sub-Saharan Africa. Glob Heart. 2017;12(2):81-90. doi:10.1016/j.gheart.2017.01.007
8. Whelton PK, Carey RM, Aronow WS, et al. 2017 ACC/AHA/ AAPA/ABC/ACPM/AGS/APhA/ASH/ASPC/NMA/PCNA guideline for the prevention, detection, evaluation, and management of high blood pressure in adults: executive summary: a report of the American College of Cardiology/American Heart Association task force on clinical practice guidelines. Circulation. 2018;138(17): e426-e483.

9. Williams B, Mancia G, Spiering W, et al. 2018 ESC/ESH guidelines for the management of arterial hypertension. The task force for the management of arterial hypertension of the European Society of Cardiology (ESC) and the European Society of Hypertension (ESH). G Ital Cardiol. 2018;19(11 Suppl 1):3S$73 \mathrm{~S}$.

10. Liu LS, Wu ZS, Wang JG. Chinese guidelines for prevention and treatment of hypertension - a report of the revision committee of Chinese guidelines for prevention and treatment of hypertension. J Geriatr Cardiol. 2019;16:182-241.

11. O'Brien E, Parati G, Stergiou G, et al. European Society of hypertension position paper on ambulatory blood pressure monitoring. J Hypertens. 2013;31(9):1731-1768. doi:10.1097/HJH.0b013e328363e964

12. Phillips RA, Sheinart KF, Godbold JH, Mahboob R, Tuhrim S. The association of blunted nocturnal blood pressure dip and stroke in a multiethnic population. Am J Hypertens. 2000;13(12):1250-1255. doi:10.1016/S0895-7061(00)01217-6

13. Hara A, Tanaka K, Ohkubo T, et al. Ambulatory versus home versus clinic blood pressure: the association with subclinical cerebrovascular diseases: the Ohasama Study. Hypertension. 2012;59(1):22-28. doi:10.1161/HYPERTENSIONAHA.111.174938

14. Hansen TW, Kikuya M, Thijs L, et al. Prognostic superiority of daytime ambulatory over conventional blood pressure in four populations: a meta-analysis of 7030 individuals. J Hypertens. 2007;25 (8):1554-1564. doi:10.1097/HJH.0b013e3281c49da5

15. Ohkubo T, Hozawa A, Nagai K, et al. Prediction of stroke by ambulatory blood pressure monitoring versus screening blood pressure measurements in a general population: the Ohasama study. J Hypertens. 2000;18 (7):847-854. doi:10.1097/00004872-200018070-00005

16. Staessen JA, Thijs L, Fagard R, et al. Predicting cardiovascular risk using conventional vs ambulatory blood pressure in older patients with systolic hypertension. Systolic hypertension in europe trial investigators. JAMA. 1999;282(6):539-546. doi:10.1001/jama.282.6.539

17. Millen AM, Norton GR, Majane $\mathrm{OH}$, et al. Insulin resistance and the relationship between urinary $\mathrm{Na}(+) / \mathrm{K}(+)$ and ambulatory blood pressure in a community of African ancestry. Am J Hypertens. 2013;26 (5):708-716. doi:10.1093/ajh/hpt010

18. Polonia J, Madede T, Silva JA, Mesquita-Bastos J, Damasceno A. Ambulatory blood pressure monitoring profile in urban African black and European white untreated hypertensive patients matched for age and sex. Blood Press Monit. 2014;19(4):192-198. doi:10.1097/ MBP.0000000000000046 
19. Etyang AO, Warne B, Kapesa S, et al. Clinical and epidemiological implications of 24-hour ambulatory blood pressure monitoring for the diagnosis of hypertension in kenyan adults: a Population-Based Study. J Am Heart Assoc. 2016;5(12). doi:10.1161/JAHA.116.004797

20. Ivy A, Tam J, Dewhurst MJ, et al. Ambulatory blood pressure monitoring to assess the white-coat effect in an elderly East African population. J Clin Hypertens. 2015;17(5):389-394. doi:10.1111/ jch. 12501

21. Lambert GW, Head GA, Chen WS, et al. Ambulatory blood pressure monitoring and morning surge in blood pressure in adult black and white South Africans. J Clin Hypertens. 2020;22(1):21-28. doi: $10.1111 /$ jch. 13740

22. Nsutebu NS, Owusu IK, Buabeng KO, Bonsu KO. Ambulatory blood pressure monitoring and management of hypertension at a cardiac clinic in Kumasi Metropolis, Ghana. J Clin Hypertens. 2020;22 (4):605-613. doi:10.1111/jch.13822

23. Bawa-Allah AB, Mashao MM, Nyundu TF, et al. Twenty-four hour ambulatory blood pressure reference values in Africans. Blood Press Monit. 2019;24(3):103-109. doi:10.1097/MBP.0000000000000376

24. Noubiap JJ, Nansseu JR, Nkeck JR, Nyaga UF, Bigna JJ. Prevalence of white coat and masked hypertension in Africa: a systematic review and meta-analysis. J Clin Hypertens. 2018. doi:10.1111/jch.13321

25. Mayige M, Kagaruki G. Tanzania STEPS Survey Report. Available from: www.who.int/ncds/surveillance/steps/UR_Tanzania_2012_ STEPS_Report.pdf. Accessed December 2, 2020. 2013.

26. National Institutes of Health. Clinical guidelines on the identification, evaluation, and treatment of overweight and obesity in adults-the evidence report. Obes Res. 1998;6(Suppl 2):51S-209S.

27. Chan JM, Rimm EB, Colditz GA, Stampfer MJ, Willett WC. Obesity, fat distribution, and weight gain as risk factors for clinical diabetes in men. Diabetes Care. 1994;17(9):961-969. doi:10.2337/ diacare.17.9.961

28. Medaval.ie. 2020. [online] Available from: https://medaval.ie/docs/ manuals/Jawon-FA-48-Manual.pdf. Accessed October 31, 2020.

29. Mancia G, De Backer G, Dominiczak A, et al. 2007 guidelines for the management of arterial hypertension: the task force for the management of arterial hypertension of the European Society of Hypertension (ESH) and of the European Society of Cardiology (ESC). $J$ Hypertens. 2007;25(6):1105-1187. doi:10.1097/ HJH.0b013e3281fc975a

30. O'Brien E, Parati G, Stergiou G. Ambulatory blood pressure measurement: what is the international consensus? Hypertension. 2013;62 (6):988-994. doi:10.1161/HYPERTENSIONAHA.113.02148

31. Kuzuya T, Nakagawa S, Satoh J, et al. Report of the Committee on the classification and diagnostic criteria of diabetes mellitus. Diabetes Res Clin Pract. 2002;55(1):65-85. doi:10.1016/S0168-8227(01) 00365-5

32. Peters SAE, Singhateh Y, Mackay D, Huxley RR, Woodward M. Total cholesterol as a risk factor for coronary heart disease and stroke in women compared with men: a systematic review and meta-analysis. Atherosclerosis. 2016;248:123-131. doi:10.1016/j. atherosclerosis.2016.03.016

33. Levey AS, Bosch JP, Lewis JB, Greene T, Rogers N, Roth D. A more accurate method to estimate glomerular filtration rate from serum creatinine: a new prediction equation. Modification of Diet in Renal Disease Study Group. Ann Intern Med. 1999;130(6):461-470. doi:10.7326/0003-4819-130-6-199903160-00002

34. Khanna D, Fitzgerald JD, Khanna PP, et al. 2012 American college of rheumatology guidelines for management of gout. Part 1: systematic nonpharmacologic and pharmacologic therapeutic approaches to hyperuricemia. Arthritis Care Res (Hoboken). 2012;64 (10):1431-1446. doi:10.1002/acr.21772

35. Bromfield S, Muntner P. High blood pressure: the leading global burden of disease risk factor and the need for worldwide prevention programs. Curr Hypertens Rep. 2013;15(3):134-136. doi:10.1007/ s11906-013-0340-9
36. Niiranen TJ, Hanninen MR, Johansson J, Reunanen A, Jula AM. Homemeasured blood pressure is a stronger predictor of cardiovascular risk than office blood pressure: the Finn-Home study. Hypertension. 2010;55 (6):1346-1351. doi:10.1161/HYPERTENSIONAHA.109.149336

37. Cai A, Liu C, Zhou D, et al. Ambulatory blood pressure is superior to clinic blood pressure in relation to ischemic stroke in both diabetic and nondiabetic patients. Blood Press Monit. 2017;22(6):314-321. doi:10.1097/MBP.0000000000000282

38. Parati G, Agabiti-Rosei E, Bakris GL, et al. MASked-unconTrolled hypERtension management based on office BP or on ambulatory blood pressure measurement (MASTER) Study: a randomised controlled trial protocol. BMJ Open. 2018;8(12):e021038. doi:10.1136/ bmjopen-2017-021038

39. Brinda EM, Andres AR, Enemark U. Correlates of out-of-pocket and catastrophic health expenditures in Tanzania: results from a national household survey. BMC Int Health Hum Rights. 2014;14:5. doi:10.1186/1472-698X-14-5

40. Leive A, Xu K. Coping with out-of-pocket health payments: empirical evidence from 15 African countries. Bull World Health Organ. 2008;86(11):849-856. doi:10.2471/BLT.07.049403

41. Felisbino-Mendes MS, Gea-Horta T, Ribeiro AL, Kac G, Silqueira SM, Velasquez-Melendez G. Association between metabolic syndrome and parameters of 24-hour blood pressure ambulatory monitoring. Arq Bras Endocrinol Metabol. 2011;55(6):383-388. doi:10.1590/S0004-27302011000600004

42. Yang WY, Melgarejo JD, Thijs L, et al. Association of office and ambulatory blood pressure with mortality and cardiovascular outcomes. JAMA. 2019;322(5):409-420. doi:10.1001/jama.2019 .9811

43. Kanno A, Kikuya M, Asayama K, et al. Night-time blood pressure is associated with the development of chronic kidney disease in a general population: the Ohasama Study. J Hypertens. 2013;31 (12):2410-2417. doi:10.1097/HJH.0b013e328364dd0f

44. Fukuda M, Munemura M, Usami T, et al. Nocturnal blood pressure is elevated with natriuresis and proteinuria as renal function deteriorates in nephropathy. Kidney Int. 2004;65(2):621-625. doi:10.1111/j.15231755.2004.00419.x

45. Zhu H, Zheng H, Liu X, Mai W, Huang Y. Clinical applications for out-of-office blood pressure monitoring. Ther Adv Chronic Dis. 2020;11:2040622320901660. doi:10.1177/2040622320901660

46. Maseko MJ, Woodiwiss AJ, Majane OH, Molebatsi N, Norton GR. Marked underestimation of blood pressure control with conventional vs. ambulatory measurements in an urban, developing community of African ancestry. Am J Hypertens. 2011;24(7):789-795. doi:10.1038/ ajh. 2011.48

47. Satoh M, Asayama K, Kikuya M, et al. Long-term stroke risk due to partial white-coat or masked hypertension based on home and ambulatory blood pressure measurements: the Ohasama Study. Hypertension. 2016;67(1):48-55. doi:10.1161/HYPERTENSIONAHA.115.06461

48. Fujiwara T, Yano Y, Hoshide S, Kanegae H, Kario K. Association of cardiovascular outcomes with masked hypertension defined by home blood pressure monitoring in a Japanese general practice population. JAMA cardiol. 2018;3(7):583-590. doi:10.1001/jamacardio.2018.1233

49. Cappuccio FP, Miller MA. Cardiovascular disease and hypertension in sub-Saharan Africa: burden, risk and interventions. Intern Emerg Med. 2016;11(3):299-305. doi:10.1007/s11739-016-1423-9

50. Chen Y, Liu JH, Zhen Z, et al. Assessment of left ventricular function and peripheral vascular arterial stiffness in patients with dipper and non-dipper hypertension. J Invest Med. 2018;66(2):319-324.

51. Ozpelit ME, Ozpelit E, Dogan NB, et al. Impact of anxiety level on circadian rhythm of blood pressure in hypertensive patients. Int J Clin Exp Med. 2015;8(9):16252-16258.

52. Walker R, Whiting D, Unwin N, et al. Stroke incidence in rural and urban Tanzania: a prospective, community-based study. Lancet Neurol. 2010;9(8):786-792. doi:10.1016/S1474-4422(10)70144-7 
53. Kayima J, Wanyenze RK, Katamba A, Leontsini E, Nuwaha F. Hypertension awareness, treatment and control in Africa: a systematic review. BMC Cardiovasc Disord. 2013;13:54. doi:10.1186/1471-2261-13-54

54. Guwatudde D, Nankya-Mutyoba J, Kalyesubula R, et al. The burden of hypertension in sub-Saharan Africa: a four-country cross sectional study. BMC Public Health. 2015;15:1211. doi:10.1186/s12889-0152546-Z

55. Hendriks ME, Wit FW, Roos MT, et al. Hypertension in sub-Saharan Africa: cross-sectional surveys in four rural and urban communities. PLoS One. 2012;7(3):e32638. doi:10.1371/journal.pone.0032638

56. Parikh NI, Pencina MJ, Wang TJ, et al. A risk score for predicting near-term incidence of hypertension: the Framingham Heart Study. Ann Intern Med. 2008;148(2):102-110. doi:10.7326/0003-4819-1482-200801150-00005
57. Everett B, Zajacova A. Gender differences in hypertension and hypertension awareness among young adults. Biodemography Soc Biol. 2015;61(1):1-17. doi:10.1080/19485565.2014.929488

58. Barlassina C, Lanzani C, Manunta P, Bianchi G. Genetics of essential hypertension: from families to genes. J Am Soc Nephrol. 2002;13 (Suppl 3):S155-S164. doi:10.1097/01.ASN.0000032524.13069.88

59. Simino J, Shi G, Bis JC, et al. Gene-age interactions in blood pressure regulation: a large-scale investigation with the CHARGE, Global BPgen, and ICBP consortia. Am J Hum Genet. 2014;95 (1):24-38. doi:10.1016/j.ajhg.2014.05.010

60. Brown CD, Higgins M, Donato KA, et al. Body mass index and the prevalence of hypertension and dyslipidemia. Obes Res. 2000;8 (9):605-619. doi:10.1038/oby.2000.79

\section{Publish your work in this journal}

Integrated Blood Pressure Control is an international, peer-reviewed open-access journal focusing on the integrated approach to managing hypertension and risk reduction. Treating the patient and comorbidities together with diet and lifestyle modification and optimizing healthcare resources through a multidisciplinary team approach constitute key features of the journal. This journal is indexed on
American Chemical Society's Chemical Abstracts Service (CAS) The manuscript management system is completely online and includes a very quick and fair peer-review system, which is all easy to use. Visit http://www.dovepress.com/testimonials.php to read real quotes from published authors. 